\title{
Lung Cancer Risk and Workplace Exposures in Black Men and Women ${ }^{1}$
}

\author{
J oshua E. Muscat, Steven D. Stellman, J ohn P. Richie J r., and Ernst L. Wynder \\ American Health Foundation, 320 East 43rd Street, New York, New York 10017
}

Received March 11, 1997

\begin{abstract}
There are little data on workplace exposures and lung cancer risk in blacks. An ongoing case-control study of lung cancer that included 550 black men and women with lung cancer and 386 age-matched controls was examined by reported occupational exposures and job titles. In men, significant associations were observed with reported exposure to asbestos [odds ratio (OR), 1.8; 95\% confidence intervals (CI) 1.03-3.1] and coal dust (OR, 2.8; 95\% CI 1.1-7.0). Elevated but nonsignificant risks of 1.4 or more were detected for the following occupations: police/security guards, farmers/farm workers, laborers, and motor-vehicle drivers. In women, nonsignificant increased risks were found with reported exposure to paint $(O R, 1.8)$ and gas fumes (OR, 4.9). Women employed as farmers/farm workers and building maintenance workers had elevated but nonsignificant risks. () 1998 Academic Press

Key Words: Iung cancer; occupation; blacks; women; asbestos.
\end{abstract}

\section{INTRODUCTION}

Lung cancer is the leading cause of cancer deaths in the U.S. The disease takes an especially large toll in blacks. The incidence rate ratio of blacks to whites is 1.5 in men and 1.1 in women (Wingo et al., 1996). The reasons for these racial disparities are unknown. The prevalence of current cigarette smoking in U.S. adults has been higher in blacks than in whites (Giovino et al., 1995; Anonymous, 1993; Giovino et al., 1994; Sterling and Weinkam, 1989), although among current smokers blacks have traditionally smoked fewer cigarettes per day (Novotny et al., 1988; Kabat et al., 1991; Hymnowitz et al.,

\footnotetext{
${ }^{1}$ This work was supported by USPHS Grants CA-17613, CA32617, and CA-68384. The study was approved by the Institutional Review Boards of all participating hospitals and the American Health Foundation. All subjects provided informed consent.
}

1995). It has been hypothesized that the higher incidence of lung cancer in blacks is related to the generally lower socioeconomic status of blacks (Stellman and Resnicow, 1997) and a concomitant greater exposure to occupational carcinogens, pollution, and poorer nutrition (Sterling and Weinkam, 1989). Despite the magnitude of the lung cancer problem in U.S. blacks, the association between occupation and lung cancer risk in blacks has rarely been studied. The current investigation uses information from a hospital-based case-control study to examine the risk of lung cancer in relation to occupation.

\section{METHODS}

A case control study of lung cancer has been conducted since 1978. The current analysis includes black subjects only and is similar to an analysis of occupational factors and lung cancer risk previously performed for white subjects (Morabia et al., 1992). In brief, newly diagnosed incident cases with histologically confirmed lung carcinoma were interviewed directly in teaching hospitals (see Acknowledgments). Case patients were interviewed at bedside after their thoracic surgical schedules were obtained. We attempted to interview similar numbers of control patients who were identified from the hospital admission lists. Eligible controls were patients admitted for conditions unrelated to tobacco use. There were many eligible controls; therefore a selection criteria was used to obtain controls that were similar to the cases by race, gender, age ( \pm 5 years), and month of diagnosis. Because the majority of patients in the hospitals were white, it was sometimes not possible to locate el igible controls after black case patients were interviewed. I nformed consent was obtained from each patient.

A standardized questionnaire was administered to each subject in the hospital by trained interviewers. The questionnaire contained detailed sections on demographics, tobacco smoking, including number of cigarettes smoked per day (CPD) and duration of 
smoking, occupation and occupational exposures, and medical history. Subjects who smoked at least one cigarette, pipe, or cigar per day in the year prior to diagnosis were designated as "current smokers." Ex-smokers were defined as those who quit smoking at least 1 year prior to diagnosis. A cumulative cigarette pack-year history was calculated by multiplying the years of smoking by the number of packs smoked per day. One pack-year of cigar ette smoking is equivalent to having smoked 20 cigarettes per day for 1 year. Subjects were asked to providetheir usual adult occupation and whether the job entailed regular exposure to a occupational exposures (a minimum of $8 \mathrm{~h}$ a week). A list of over 40 occupational exposures was provided.

Frequency tables and $\chi^{2}$ analyses were calculated to compare proportions. Odds ratios $(\mathrm{OR})^{2}$ derived from unconditional logistic regression estimates (Breslow and Day, 1990) together with 95\% confidence intervals $(\mathrm{Cl})$ were obtained after adjusting for age (four categories), education (four categories) and smoking (four levels of pack-years). Multiple occupational exposures were assessed using Kendall's $\tau$-b coefficient.

\section{RESULTS}

Five hundred and fifty case patients ( 365 men and 185 women) were included in the analysis. A basic description of the subjects is shown in Table 1. The mean age of cases was 58.9 in men and 58.6 in women. There were no differences in levels of education between male cases and controls (10.3 years versus 11.0 years). In women, controls were more highly educated than cases (12.3 years versus 11.3 years, $\mathrm{P}=0.01$ ). As expected, a higher proportion of cases currently smoked cigarettes, and among current smokers, cases smoked more cigarettes per day than controls (Table 1 ).

Table 2 shows the distribution of reported occupational exposures between cases and controls, ranked by the frequency of exposure (in men). Among men, the most commonly reported occupational exposures in controls were oil $(21.6 \%)$, highway exhaust $(15.1 \%)$, metal dust $(14.3 \%)$, paint $(12.7 \%)$, solvents $(11.2 \%)$, fumes $(10.8 \%)$, and asbestos/insulation $(10.4 \%)$. After adjustment for age, education, and smoking status, the only significant associations with lung cancer were with reported asbestos/insulation exposure (OR, 1.8; 95\% $\mathrm{Cl} 1.03-3.1)$ and coal dust (OR, 2.8; 95\% Cl 1.1-7.0). Nonsignificant but

\footnotetext{
${ }^{2}$ Abbreviations used: OR, odds ratios; $\mathrm{Cl}$, confidence intervals.
}

TABLE 1

Characteristics of Lung Cancer Patients and Controls, 1978-1996

\begin{tabular}{|c|c|c|c|c|}
\hline \multirow[b]{2}{*}{ Characteristic } & \multicolumn{2}{|c|}{ Males } & \multicolumn{2}{|c|}{ Females } \\
\hline & $\begin{array}{c}\text { Cases } \\
(\mathrm{N}=365) \\
\%\end{array}$ & $\begin{array}{c}\text { Controls } \\
(\mathrm{N}=251) \\
\%\end{array}$ & $\begin{array}{c}\text { Cases } \\
(\mathrm{N}=185) \\
\%\end{array}$ & $\begin{array}{c}\text { Controls } \\
(\mathrm{N}=135) \\
\%\end{array}$ \\
\hline \multicolumn{5}{|l|}{ Age } \\
\hline$<45$ & 6.6 & 8.8 & 9.7 & 5.9 \\
\hline $45-54$ & 23.6 & 19.1 & 22.2 & 25.9 \\
\hline $55-64$ & 41.0 & 46.2 & 46.0 & 37.8 \\
\hline $65-74$ & 25.8 & 22.7 & 17.8 & 28.9 \\
\hline$\geq 75$ & 3.0 & 3.2 & 4.3 & 1.5 \\
\hline \multicolumn{5}{|c|}{ Education (years) } \\
\hline$\leq 12$ & 53.4 & 47.8 & 43.2 & 33.3 \\
\hline 12 & 25.2 & 27.3 & 34.4 & 32.6 \\
\hline $13-15$ & 12.0 & 13.3 & 14.8 & 16.3 \\
\hline$\geq 16$ & 9.3 & 11.7 & 7.7 & 17.8 \\
\hline \multicolumn{5}{|l|}{ Smoking } \\
\hline Never & 10.2 & 22.3 & 9.7 & 57.5 \\
\hline Current & 66.8 & 35.4 & 65.4 & 28.4 \\
\hline Former & 23.0 & 42.3 & 24.9 & 14.2 \\
\hline Pipe/cigar & 1.9 & 4.0 & 0.0 & 0.0 \\
\hline \multicolumn{5}{|l|}{ Cigarettes/day ${ }^{a}$} \\
\hline $1-20$ & 61.9 & 84.3 & 61.2 & 84.2 \\
\hline 21-39 & 19.4 & 6.9 & 23.1 & 7.9 \\
\hline$\geq 40$ & 18.6 & 8.8 & 15.7 & 7.9 \\
\hline
\end{tabular}

${ }^{\text {a }}$ Current smokers.

elevated odds ratios were found with pesticides, dry cleaning, stone dust, and wood dust. No association was observed with diesel engine exhaust. Few patients were exposed to radiation or rubber. Exposure to elemental lung carcinogens including arsenic, beryllium, chromium, and nickel was virtually absent. For all exposures, there was little difference in risk when stratifying by the histologic type of lung cancer. For example, $13.6 \%$ of male cases with squamous cell cancer and $16.5 \%$ of male cases with adenocarcinoma reported asbestos exposure. There was no evidence of an interaction between occupational exposures and pack-years of smoking although statistical power to detect interactions was limited. A correlation matrix of reported occupational substances revealed a few common exposures in men. Among the more common exposures, the highest correlations were for asbestos and wood $(r=0.19)$ and solvents and paint $(r=0.16)$. Asbestos exposure was also correlated with fiberglass $(r=$ $0.26)$. In contrast to the men, few women reported exposure to occupational substances (Table 2 ). 
TABLE 2

Distribution of Occupational Exposures in Black Men and Women, 1978-1996

\begin{tabular}{|c|c|c|c|c|c|c|c|c|}
\hline \multirow{2}{*}{$\begin{array}{l}\text { Ocupational } \\
\text { exposures }\end{array}$} & \multicolumn{4}{|c|}{ Men } & \multicolumn{4}{|c|}{ Women } \\
\hline & Cases & Controls & OR & $95 \% \mathrm{Cl}$ & Cases & Controls & OR & $95 \% \mathrm{Cl}$ \\
\hline Oil & 14.9 & 21.6 & 0.6 & $0.4-0.9$ & 4.9 & 1.5 & 1.7 & $0.3-9.8$ \\
\hline Highway & 10.8 & 15.1 & 0.9 & $0.4-1.2$ & 0.5 & 0.7 & 0.9 & $0.0-32.9$ \\
\hline Metal dust & 12.9 & 14.3 & 0.8 & $0.5-1.3$ & 2.7 & 2.2 & 0.7 & $0.1-3.7$ \\
\hline Paint & 8.2 & 12.7 & 0.7 & $0.3-1.1$ & 2.7 & 0.7 & 1.8 & $0.3-12.3$ \\
\hline Solvents & 8.5 & 11.2 & 0.6 & $0.3-1.1$ & 0.5 & 0.7 & 1.1 & $0.3-4.8$ \\
\hline Gas fumes & 8.8 & 10.8 & 0.7 & $0.4-1.2$ & 3.2 & 1.5 & 7.1 & $1.2-41.8$ \\
\hline Asbestos & 15.8 & 10.4 & 1.8 & $1.03-3.1$ & 3.2 & 3.7 & 1.0 & $0.2-4.6$ \\
\hline Wood dust & 10.8 & 6.8 & 1.6 & $0.8-3.2$ & 0.0 & 0.7 & - & \\
\hline Coke & 4.4 & 4.6 & 0.7 & $0.3-1.6$ & 0.0 & 0.0 & - & \\
\hline Stone dust & 7.6 & 3.9 & 1.6 & $0.7-3.7$ & 0.0 & 0.7 & - & \\
\hline Chemicals & 2.3 & 3.5 & 0.7 & $0.2-1.9$ & 2.2 & 0.0 & - & \\
\hline Diesel exhaust & 2.9 & 3.1 & 0.9 & $0.3-2.6$ & 0.0 & 0.7 & - & \\
\hline Fiberglass & 4.1 & 3.1 & 1.1 & $0.4-2.7$ & 0.0 & 0.7 & - & \\
\hline Coal dust & 7.6 & 3.1 & 2.8 & $1.1-7.0$ & 1.1 & 1.5 & 0.5 & $0.1-4.8$ \\
\hline Tar & 2.9 & 2.7 & 1.3 & $0.4-4.1$ & 0.0 & 0.0 & - & \\
\hline Heat & 3.2 & 2.3 & 1.2 & $0.4-3.4$ & 1.0 & 0.0 & - & \\
\hline Dyes & 2.9 & 2.3 & 1.1 & $0.4-3.3$ & 4.3 & 5.2 & 0.5 & $0.2-1.7$ \\
\hline Textiles & 2.6 & 1.5 & 1.4 & $0.4-5.2$ & 6.5 & 3.7 & 1.9 & $0.5-6.4$ \\
\hline Plastic & 3.2 & 1.9 & 2.3 & $0.7-7.8$ & 1.6 & 2.2 & 0.5 & $0.1-3.5$ \\
\hline Radiation & 0.9 & 1.2 & 0.5 & $0.1-2.5$ & 0.5 & 1.5 & 1.6 & $0.1-19.7$ \\
\hline Pesticides & 3.5 & 1.2 & 2.4 & $0.7-8.9$ & 0.5 & 0.0 & - & \\
\hline Dry cleaning & 2.3 & 1.2 & 2.3 & $0.4-13.0$ & 3.2 & 2.2 & 0.7 & $0.2-2.8$ \\
\hline
\end{tabular}

Note Odds ratios adjusted for age, education, and pack-years of smoking by logistic regression methods.

There was no significant association between any specific job category and lung cancer risk (Table 3). In men, nonsignificant associations were found with police/security workers (OR, 2.0), farmers/farm workers (OR, 1.7), and drivers (OR, 1.5). In women, nonsignificant elevated risks were observed for farmers/farm workers (OR, 2.0), building maintenance workers (OR, 2.5), and clerical workers (OR, 1.5).

TABLE 3

Usual Occupation in Black Men and Women, 1978-1996

\begin{tabular}{|c|c|c|c|c|c|c|c|c|}
\hline \multirow[b]{2}{*}{ J ob category } & \multicolumn{4}{|c|}{ Men } & \multicolumn{4}{|c|}{ Women } \\
\hline & Cases & Controls & OR & $95 \% \mathrm{Cl}$ & Cases & Controls & OR & $95 \% \mathrm{Cl}$ \\
\hline Professional $^{a}$ & 5.6 & 9.7 & 1.0 & $0.4-2.1$ & 9.7 & 22.5 & 0.7 & $0.3-1.7$ \\
\hline Managerial & 5.0 & 5.4 & 1.2 & $0.5-2.8$ & 3.9 & 2.8 & 1.4 & $0.3-5.7$ \\
\hline Sales & 1.2 & 1.5 & 0.9 & $0.2-4.5$ & 3.8 & 0.0 & - & \\
\hline Clerical & 8.8 & 6.6 & 1.3 & $0.7-2.6$ & 26.0 & 17.6 & 1.5 & $0.7-2.8$ \\
\hline Construction & 11.1 & 10.0 & 1.0 & $0.6-1.9$ & - & - & - & \\
\hline Mechanics & 1.8 & 2.3 & 0.6 & $0.2-2.1$ & - & - & - & \\
\hline Other skilled labor & 13.7 & 19.3 & 0.7 & $0.4-1.0$ & 4.4 & 5.6 & 0.7 & $0.2-2.1$ \\
\hline Police/security guard & 3.2 & 1.2 & 2.0 & $0.5-7.9$ & 1.1 & - & - & \\
\hline Semi-skilled & 11.4 & 15.8 & 0.7 & $0.4-1.2$ & 11.1 & 9.9 & 1.0 & $0.4-2.3$ \\
\hline Drivers & 16.1 & 10.8 & 1.5 & $0.9-2.5$ & 1.1 & - & - & \\
\hline Laborers & 8.2 & 5.0 & 1.6 & $0.7-3.3$ & 0.6 & 1.4 & 0.2 & $0.0-2.4$ \\
\hline Railroad workers & 0.9 & 1.2 & 0.7 & $0.1-4.1$ & 0.0 & 0.0 & - & \\
\hline Building maintenance & 4.4 & 3.1 & 1.2 & $0.5-2.9$ & 3.9 & 2.8 & 2.5 & $0.5-13.4$ \\
\hline Farm work & 2.1 & 1.2 & 1.7 & $0.3-8.7$ & 1.6 & 1.4 & 2.0 & $0.2-19.1$ \\
\hline Service workers ${ }^{b}$ & 6.1 & 6.2 & 0.8 & $0.4-1.7$ & 32.0 & 34.5 & 0.6 & $0.3-1.2$ \\
\hline Never worked & 0.6 & 0.4 & 2.9 & $0.2-50.9$ & 0.6 & 1.4 & 0.2 & $0.02-3.1$ \\
\hline
\end{tabular}

a Includes accountants, computer analysts, engineers, lawyers, nurses, physicians, professors, scientists, social workers, teachers, etc. bI ncludes food workers and handlers, domestic workers, housewife, nurses'aides, etc.

Note Odds ratios adjusted for age, education, and pack-years of smoking by logistic regression methods. 


\section{DISCUSSION}

Many occupational exposures are listed as possible lung carcinogens by the International Agency on Research for Cancer (Steenland et al., 1996), including heavy metals, vehicle emissions, asbestos, and radon. I dentifying occupational carcinogens has historically been difficult because skilled industrial workers are often exposed simultaneously to many airborne pollutants, and studies of occupational cohorts have often lacked data on smoking habits. It has been speculated that occupational exposures play an important role in lung cancer mortality in blacks. Miller and Cooper (1982) reported large racial differences in exposure to environmental and occupational hazards. However, few studies have examined occupation and the risk of lung cancer in blacks. In a population-based study of black men, Swanson et al. (1993) found increased risks for lung cancer among farm workers, automobile mechanics, painting machine operators, furnace operators, garbage collectors, and cutting machine operators in Michigan. In a study of coke oven workers, 33 of 35 lung cancers occurred among blacks (Mancuso and Sterling, 1975).

In our study, the significantly increased risk associated with reported asbestos exposure is consistent with the known carcinogenic effects of this mineral. The elevated risks found for building maintenance personnel in women likely reflect exposure to friable asbestos. Swanson et al. (1993) also observed evidence of increased risks in black men with possible or likely asbestos exposure. In that study, associations were found for concrete finishers, automobile mechanics, construction workers, and railroad workers.

We found associations with reported exposure to dusts from coal, wood, and stone. Small increased risks of lung cancer associated with self-reported workplace exposure to coal dust have been reported in case-control studies (Morabia et al., 1992; WuWilliams et al., 1993) and in Swedish chimney sweeps (Gustavsson et al., 1988). However, most studies of lung cancer in coal miners have not demonstrated an excess occurrence (Mancuso et al., 1975; Meijers et al., 1988). Increased rates of lung cancer in stone workers have been reported in Germany (Vutuc, 1983), Austria (Neuberger and Kundi, 1990), Finland (Lynge et al., 1986), and Denmark (Guenel et al., 1986) but not in Switzerland (Schuler et al., 1982). This group is not exposed to other known lung carcinogens, although it needs to be determined whether the excess rates in some of these studies reflect higher smoking prevalences. Case control data show increased lung cancer risk with reported exposure to wood dust (Blot et al., 1982; N otani et al., 1993). In a study of 113 blacks, wood dust exposure was significantly linked to lung cancer (OR, 5.5; $9.5 \% \mathrm{Cl}$ 1.6-18.9); there was suggestive evidence of an interactive effect with smoking (Wu et al., 1995). Exposure to wood dust may occur in conjunction with asbestos, as was the case for some subjects in our data, or formal dehyde, although these studies suggest that further investigations of wood dust as a possible lung carcinogen are warranted. Less than $5 \%$ of male cases and controls in this study were exposed to coke oven effluents. None of the women reported exposure to coke ovens. Other petrochemical exposures were unrelated to lung cancer risk. An increased risk was observed for drivers, which agrees with much occupational data. In contrast, there was no association with reported diesel exhaust, which is consistent with our previous report on this issue in mostly white subjects (Boffetta et al., 1989).

An elevated risk of lung cancer in men who were exposed to workplace pesticides was found. Only one female case self-reported exposure to pesticides. In addition, although there were few farmers or farm workers in this study, both men and women in this group experienced an increased risk of lung cancer; a similar finding was reported by Swanson et al. (1993). Studies of industrial workers exposed to pesticides are somewhat equivocal and hampered by relatively small cohorts (Steenland et al., 1996). Two studies (Ott et al., 1974; Mabuchi et al., 1979) show elevated rates of lung cancer in workers exposed to arsenic-containing pesticides and imply that this excess is unlikely to be due to smoking. Other studies found reduced (Blair et al., 1985; Zahm et al., 1989; Fincham et al., 1992; McDuffie et al., 1990; Carstensen et al., 1988; Damber and Larsson, 1987) or increased risks (Benhamou et al., 1988) of lung cancer in farmers. Use of pesticides was significantly associated with lung cancer risk in nonsmoking women (Brownson et al., 1993). Increased risks in men were also found with exposure to plastics and dry-cleaning chemicals, although these associations were based on few subjects. Elevated risks were noted for policemen/security guards.

The case-control method in occupational epidemiology has some attractive features over other study designs. In our study, over $90 \%$ of eligible participants who were approached agreed to be interviewed. All interviews were done in person using trained interviewers. Exposure information was obtained from patients and not next-of-kin or death certificates. This allowed for detailed ascertainment of lifetime smoking, employment history, and 
exposure to specific occupational hazards. There are also several limitations of this type of analysis. The use of a large ongoing multicenter study enabled us to examine occupational risk factors for a subset of black patients, although it was not possible to obtain a control for each case. Because there was a wide variety of employment experience, statistical power for any individual occupation is low. The data were collected over a long period of time and may not reflect changes in workplace safety standards. The multiple comparisons increase the likelihood of typel errors. As in all hospital-based studies, the control patients are persons admitted for acute or chronic illnesses, some of which may be job-related. Further, while the specificity of self-reporting to most occupational exposures is high, the sensitivity ranges from low to high depending on the type of exposure. Fritschi et al. (1996) compared selfreported exposure to expert-assessed exposure for 11 common occupational exposures in 1910 men. Sensitivity values of under 0.5 were calculated for plastic, rubber, gasoline and fuel oils, lubricating oils, and grease. Sensitivity values were 0.51 for asbestos, 0.53 for pesticides, and 0.60 for wood exposure. The low exposure to plastic and rubber in this study may reflect underreporting, and it clearly was not possible to conduct industrial hygiene surveys in the workplaces of the study subjects. In addition, recall bias must always be acknowledged in determining past experiences. Despitethese limitations, our findings of increased risks with asbestos exposure, various occupational dusts, pesticides, and several occupational groups are consistent with many other reports. These data may be helpful in identifying possible employment hazards and high-risk occupations for blacks.

The hazards faced by women on the job have not been extensively studied, possibly because of the historical perception that women's work has been predominately confined to social and familial roles. Contrary to this perception, many women have been employed in a wide variety of industrial and manufacturing settings and are exposed to a variety of biological, chemical, and physical hazards (Stellman, 1994), some with potential exposure to carcinogens (Stellman and Stellman, 1995). Lung cancer risk and employment history in women has not been extensively studied in the U.S. In particular, there have been no previous studies of occupation and lung cancer risk in black women. One populationbased study in N ew Mexico found no effect of occupation in women, although the sample size was not large (Lerchen et al., 1987). Swanson and Burns (1995) reported increased lung cancer incidence for women employed in the manufacturing of fabricated and ferrous metals, clay, computers, and rubberplastics. Further efforts in this area of investigation should consider that cancer incidence and mortality in women may involve factors beyond physical exposure to workplace carcinogens.

The current data suggest that occupational exposures contribute to the lung cancer burden in at least black men and that occupational exposures to lung carcinogens may be more common in blacks than in whites. Comparing the rate of asbestos exposure between black and white subjects who were interviewed during the study period shows that $10.4 \%$ of black controls were exposed to asbestos versus $6.3 \%$ of white controls. Similarly, $15.6 \%$ of black cases and $11.8 \%$ of white cases were exposed to asbestos. Swanson et al. (1993) found a higher burden of total occupational exposures in black men than in white men. However, caution is required before making inferences regarding racial differences in cancer rates due to occupation. Mesothelioma is caused almost exclusively by asbestos, yet the 1988-1992 incidence rate for pleural mesothelioma in the SEER program is higher in white men than in black men (1.7 vs 0.9 per 100,000 ).

Recent studies show racial differences in the capacity to metabolize the tobacco-specific carcinogen 4-(methylnitrosamino)-1-(3-pyridyl)-1-butanone (NNK). Richie et al. (1997) studied 61 healthy black and white smokers and found that $26 \%$ of whites were characterized phenotypically as extensive metabolizers of NNK, compared to $6 \%$ of blacks. NNK is a potent carcinogen for primitive lung adenocarcinoma in laboratory animals (Hecht and Hoffmann, 1988). In addition to smoking and occupation, another possible explanation for the excess rates of lung cancer in blacks is poor nutrition. Further work in minority health and lung cancer should focus on the relative contribution of smoking, occupation, diet, and combinations of these risk factors.

\section{ACKNOWLEDGMENTS}

The authors express their gratitudeto Marion Moore and Anna
Mondora, field supervisors, and to the following individuals and
institutions: Elliot Strong, M.D., Newton Morton, M.D., Susan
Harlap, M.D., Zuo-Feng Zhang, M.D., Ph.D., and Marianne
Berwick, Ph.D., Memorial Sloan-Kettering Cancer Center, New
York, NY; Ronald H. Blum, M.D., and William Rom, M.D., New
York University Medical Center; Alfred I. Neugut, M.D., Ph.D.,
Columbia University School of Public Health, New York, NY;
Philip Witorsch, M.D., George Washington University Medical
Center, Washington, D.C.; Edward Garrity J r., M.D., Loyola Uni-
versity Hospital, Chicago, IL; J ohn Sharp, M.D., Hines, IL;
Christine J ohnson, Ph.D., Henry Ford Hospital, Detroit, MI;
Kanti Rai, M.D., Marc Citron, M.D., Long Island J ewish Medical 
Center, New Hyde Park, NY; Linga Ragu, M.D., Nassau County Medical Center, E ast Meadow, NY; J ames Colberg, M.D., Thomas J efferson University Hospital, Philadelphia, PA; and Paul Stolley, M.D., Hospital of the University of Pennsylvania, Philadel phia, PA.

\section{REFERENCES}

Anonymous (1994). Cigarette smoking among adults-United States, 1993. MMWR Morb. Mortal. Wkly. Rep. 43, 925-930.

Benhamou, S., Benhamou, E., and Flamant, R. (1988). Occupational risk factors of lung cancer in a F rench case-control study. Br. J . Indust. Med. 45, 231-233.

Blair, A., Malker, H., Cantor, K., Burmeister, L., and Wiklund, K. (1985). Cancer among farmers. Scand. J . Work Environ. Health 11, 397-407.

Blot, W. J ., Davies, J . E., Brown, L. M., Nordwall, C. W., Buiatti, E., Nag, A., et al. (1982). Occupation and the high risk of lung cancer in Northeast Florida. Cancer 50, 364-371.

Boffetta, P., Harris, R. E., and Wynder, E. L. (1989). Diesel exhaust and lung cancer. Exp. Pathol. 37, 32-38.

Breslow, N. E., and Day, N. E. (1980) "Statistical Methods in Caner Research," Vol. 1, "The Analysis of Case-Control Studies," pp. 192-246. International Association for Research on Cancer, Lyon, France.

Brownson, R. C., Alavanja, M. C., and Chang, J . C. (1993). Occupational risk factors for lung cancer among nonsmoking women: A case-control study in Missouri (United States). Cancer Causes Control 4, 449-454.

Carstensen, J . M., Pershagen, G., and Eklund, G. (1988). Smoking-adjusted incidence of lung cancer among Swedish men in different occupations. Int. J . Epidemiol. 17, 753-758.

Damber, L. A., and Larsson, L. G. (1987). Occupation and male lung cancer: A case-control study in northern Sweden. Br. J . Indust. Med. 44, 446-453.

Fincham, S. M., Hanson, J ., and Berkel, J . (1992). Patterns and risks of cancer in farmers in Alberta. Cancer 69, 1276-1285.

Fritschi, L., Siemiatycki, J ., and Richardson, L. (1996). Selfassessed versus expert-assessed occupational exposures. Am. J . Epidemiol. 144, 521-527.

Giovino, G. A., Schooley, M. W., Zhu, B. P., et al. (1994). Surveillance for selected tobacco-use behaviors-United States, 1900-1994. MMWR CDC Surv. Summ. 43, 1-43.

Giovino, G. A., Henningfield, J . E., Tomar, S. L., Escobedo, L. G., and Slade, J . (1995). E pidemiology of tobacco use and dependence. Epidemiol. Rev. 17, 48-65.

Guenel, P., Hojberg, G., and Lynge, E. (1989). Cancer incidence among Danish stone workers. Scand. J . Work Environ. Health 15, 265-270.

Gustavsson, P., Gustavsson, A., and Hogstedt, C. (1988). Excess of cancer in Swedish chimney sweeps. Br. J. Indust. Med. 45, 777-781.

Hecht, S. S., and Hoffmann, D. (1988). Tobacco-specific nitrosamines, an important group of carcinogens in tobacco and tobacco smoke. Carcinogenesis 9, 875-884.

Hymowitz, N., Corle, D., Royce, J ., Hartwell, T., Corbett, K., Orlandi, M., Piland, N., et al. (1995). Smokers' baseline characteristics in the COMMIT trial. Prev. Med. 24, 503-508.
Kabat, G. C., Morabia, A., and Wynder, E. L. (1991). Comparison of smoking habits of Blacks and Whites in a case-control study. Am. J . Public Health 81, 1483-1486.

Lerchen, M. L., Wiggins, C. L., and Samet, J. M. (1987). Lung cancer and occupation in New Mexico. J . Natl. Cancer Inst. 79, 639-645.

Lynge, E., Kurppa, K., Kristofersen, L., Malker, H., and Sauli, H. (1986). Silica dust and lung cancer: Results from the Nordic occupational mortality and cancer incidence registers. J . Natl. Cancer Inst. 77, 883-889.

Mabuchi, K., Lilienfeld, A. M., and Snell, L. M. (1979). Lung cancer among pesticide workers exposed to inorganic arsenicals. Arch. Environ. Health 34, 312-320.

Mancuso, T. F., and Sterling, T. D. (1975). Lung cancer among black and white migrants in the U.S. J . Natl. Med. Assoc. 67, 106-111.

McDuffie, H. H., Klaassen, D. J ., and Dosman, J. A. (1990). Is pesticide use related to the risk of primary lung cancer in Saskatchewan? J . Occup. Med. 32, 996-1002.

Meijers, J. M., Swaen, G. M., Slangen, J . J ., and van Vliet, C. (1988). Lung cancer among Dutch coal miners: A case-control study. Am. J . Indust. Med. 14, 597-604.

Miller, W. J ., and Cooper, R. (1982). Rising lung cancer death rates among black men: The importance of occupation and social class. J. Natl. Med. Assoc. 74, 253-258.

Morabia, A., Markowitz, S., Garibaldi, K., and Wynder, E. L. (1992). Lung cancer and occupation: Results of a multicentre case-control study. Br. J . Indust. Med. 49, 721-727.

Neuberger, M., and Kundi, M. (1990). Occupational dust exposure and cancer mortality-Results of a prospective cohort study. IARC Sci. Pub. 97, 65-73.

Notani, P. N., Shah, P., J ayant, K., and Balakrishnan, V. (1993). Occupation and cancers of the lung and bladder: A case-control study in Bombay. Int. J . Epidemiol. 22, 185-191.

Novotny, T. E., Warner, K. E., Kendrick, J . S., and Remington, P. L. (1988). Smoking by Blacks and Whites: Socioeconomic and demographic differences. Am. J . Public Health 78, 1187-1189.

Ott, M. G., Holder, B. B., and Gordon, H. L. (1974). Respiratory cancer and occupational exposures to arsenicals. Arch. Environ. Health 29, 250-255.

Richie, J . P., J r., Carmella, S., Muscat, J ., Scott, D. S., Akerkar, S., and Hecht, S. S. (1997). Racial differences in the urinary metabolites of NNK. Cancer Epidemiol. Biomarkers Prev. 6, 783-790.

Schuler, G., Walchi, P., Ruttner, J . R., Delmore, M., Taylor, M., et al. (1982). Incidence of lung cancer and age at death in silicosis deaths of the Swiss National Accident Insurance Fund, 1960-1978. Soz. Praventivmed. 27, 218-219. [German]

Steenland, K., Looms, D., Shy, C., and Simonsen, N. (1996). Review of occupational lung carcinogens. Am. J . Indust. Med. 29, $474-490$.

Stellman, J . M. (1994). Where women work and the hazards they may face on the job. J . Occup. Med. 36, 814-825.

Stellman, J . M., and Stellman, S. D. (1995). Social factors: Women and cancer. Semin. Oncol. Nursing 11, 103-108.

Stellman, S. D., and Resnicow, K. (1997). Tobacco smoking, cancer and social class. In "Social Inequalities and Cancer" (M. Kogevinas, N. Pearce, M. Susser, and P. Boffetta, Eds.), pp. 229-250. IARC Scientific Publications No. 138. Lyon: International Agency for Research on Cancer. 
Sterling, T. D., and Weinkam, J . J . (1989). Comparison of smoking-related risk factors among black and white males. Am. J . Indust. Med. 15, 319-333.

Swanson, G. M., Lin, C. S., and Burns, P. B. (1993). Diversity in the association between occupation and lung cancer among black and white men. Cancer Epidemiol. Biomarkers Prev. 2, 313-320.

Swanson, G. M., and Burns, P. B. (1995). Cancer incidence among women in the workplace: A study of the association between occupation and industry and 11 cancer sites. J . Occup. Environ. Med. 37, 282-287.

Vutuc, C. (1983). Risk of lung cancer bel onging to the occupational group of mining and stone processing. Zentralbl. Bakteriol. Mikrobiol. Hyg. Abt. 1 Orig. B 177, 183-187. [German]
Wingo, P. A., Bolden, S., Tong, T., Parker, S. L., Martin, L. M., and Health, C. W., J r. (1996). Cancer statistics for African Americans, 1996. Ca. Cancer J . Clin. 46, 113-125.

Wu, X., Delclos, G. L., Annegers, J . F., Bondy, M. L., Honn, S. E., and Henry, B., et al. (1995). A case-control study of wood dust exposure, mutagen sensitivity, and lung cancer risk. Cancer Epidemiol. Biomarkers Prev. 4, 583-588.

Wu-Williams, A. H., Xu, Z. Y., Blot, W. J ., Dai, X. D., Louie, R., Xiao, H. P., et al. (1993). Occupation and lung cancer risk among women in northern China. Am. J . Indust. Med. 24, 67-79.

Zahm, S., Brownson, R., Chang, J ., and Davis, J . (1989). Study of lung cancer histological types, occupation, and smoking in Missouri. Am. J . Ind. Med. 15, 565-578. 